\title{
Using Two-Way Prestressed Semicircular Steel Plate for Construction of Reinforced Concrete Cylinder Column
}

\author{
Zhenhua Ren, ${ }^{1,2}$ Xiantao Zeng $\mathbb{D}^{1}{ }^{1}$ and Junbo Sun ${ }^{2}$ \\ ${ }^{1}$ School of Building Engineering of Hunan Institute of Engineering, Xiangtan 411104, China \\ ${ }^{2}$ School of Civil, Environmental, and Mining Engineering, University of Western Australia, Perth, WA 6009, Australia \\ Correspondence should be addressed to Xiantao Zeng; xtzeng63@163.com
}

Received 5 April 2018; Revised 11 June 2018; Accepted 21 June 2018; Published 30 July 2018

Academic Editor: Diyi Chen

Copyright (C) 2018 Zhenhua Ren et al. This is an open access article distributed under the Creative Commons Attribution License, which permits unrestricted use, distribution, and reproduction in any medium, provided the original work is properly cited.

\begin{abstract}
A concrete column has a significant influence on constructions because the component withstands the major weight of the whole structure. However, the ordinary concrete column has limited capacity to resist to multiaxial loadings. Since steel plate is one of the most common materials used in construction, concrete reinforced with steel plates based on prestressing reinforcement technology would be a directly applicable solution to the enhancement of mechanical property. In this study, a new reinforcement method upon concrete cylinder column used a two-way prestressed semicircular steel plate, which has already been patented. The study firstly analyzed the stress-bearing situation of the short concrete column reinforced by a two-way prestressed semicircular steel plate. The considerable substitution effect of vertical prestressing force on the concrete column was explored. The multiple restriction effects of horizontal prestressing force, semicircular steel plate, and stirrup were examined. Thereby, the calculation model was derived for the prestressed structure. Secondly, the formula was verified by experiments with close agreements. The result indicated that a unified strength theory was applicable to the theoretical calculation for short concrete column reinforced with a prestressed semicircular steel plate under axial compression, providing the foundation for analytical computation of prestressed semicircular steel plate-reinforced concrete column structures.
\end{abstract}

\section{Introduction}

Reinforcement methods for concrete column largely include a section expansion method, spiral bar constraint method, steelwrapping reinforcement method, fiber-reinforced polymer reinforcement method, composite reinforcement method, axial prestressed strut reinforcement method, steel plate reinforcement method, and prestressed steel strip (steel strand) reinforcement method. The section expansion method, spiral bar constraint method, steel-wrapping reinforcement method, fiber-reinforced polymer reinforcement method, and composite reinforcement method lay the emphasis on horizontal column reinforcement and enlarge the sectional area of the concrete column while improving its axial bearing capacity. Stress hysteresis phenomenon exists in subsequently added materials, and wrapped original concrete column is under a passive three-dimensional stress state. The last two methods focus on axial reinforcement of concrete column, which will also enlarge the transverse scale of the concrete column.

The circular steel tube reinforcement method (as shown in Figure 1) has developed rapidly in recent decades [1-11], which origins in the application of cylinder columns. Concrete reinforcement using a circular steel tube can improve the bearing capacity of the concrete column as well as ductility. Its reinforcement pattern can be divided into three types: hoop reinforcement (Figure 1(a)), complete reinforcement (Figure 1(b)), and local reinforcement (Figure 1(c)) according to the height of the concrete column itself and height of the circular steel tube [1].

The literature relevant to the circular steel tube reinforcement method focuses on the axial compression bearing capacity [1-8] and seismic performance [9-11]. It is concluded that (1) the method gives rise to the shear bearing capacity of the concrete column. This is because the circular steel tube can be regarded as a densely arranged hoop to withstand 


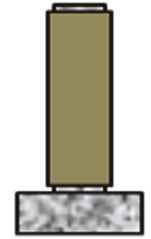

(a) Hooping

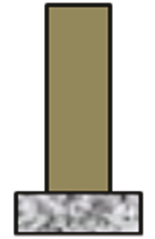

(b) Fully

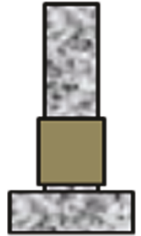

(c) Part strengthening strengthening strengthening

FIgURE 1: Concrete columns strengthened with circular steel tube.

shear forces. Under the effect of horizontal seismic force, bending failure is thus guaranteed to firstly occur in order to transform brittle shear failure into ductile bending failure. (2) The method improves the flexural capacity of the concrete column. The lateral constraint of the steel tube restricts lateral expansion of concrete in compression zone and lap joints longitudinally. The constraint effect guarantees the bearing capacity and ductility of the reinforced concrete column. Common reinforcement methodologies are shown in Figures 1(a) and 1(b). Besides, plastic hinge reinforcement solution is normally utilized when dissipation of seismic energy mainly relies on the plastic hinge. The structure is demonstrated in Figure 1(c). (3) The method enhances the vertical bearing capacity of the concrete column. The steel tube prevents the failure of concrete cover to cooperate with improved longitudinal reinforcement against lateral loading. Except for the bearing capacity, rigidity and ductility were improved by the steel tube (Figure 1(a)).

In terms of studies of circular steel tube reinforcement methods, the crucial issues are mainly found in the static loading test and bearing capacity of steel tube-reinforced concrete column. There are few studies of influences of the steel tube constraint effect and performance of the bond between fresh and hardened concretes on bearing capacity or dynamic characteristics of the concrete column after reinforcement, like seismic performance. The main problems of the method lie in the following: (1) the interface between fresh and hardened concretes is unconstrained connection with a nonhigh load transfer effect; (2) the interface between fresh and hardened concretes is the failure interface; (3) stress hysteresis exists in fresh concrete, and fresh concrete and steel tube can exert an effect only when the concrete column further deforms; and (4) the circular steel tube does not directly bear vertical load, and its effect is similar to reinforced stirrup, which will result in waste of materials.

As aforementioned, most reinforcing methods mainly rely on the lateral constraint to improve the mechanical performance of the concrete column. However, based on those methods, only by considerable deformation of concrete can the reinforcing components work, resulting in ineffective utilization of reinforcing materials.

In order to overcome stress and strain hysteresis to enhance the reinforcement effect, the prestressed horizontal constraint method is employed. The method enables the concrete to bear loading in a three-way with active stress state, contributing to higher bearing capacity and deformation performance of the concrete. Reinforcement methods using active prestressing force constraints are proposed both home and abroad like the prestressed steel tube (plate) hoop reinforcement method [12-19], prestressed fiberboard reinforcement method [20], shape-memory alloy stirrup reinforcement method [21,22], and prestressed steel strand reinforcement method [23].

Transverse prestressing force actively constrains core concrete so that both bearing capacity and deformation performance of reinforced concrete column are improved. Its construction is shown in Figure 2 [12]. The test indicates that the prestressed steel plate hoop can effectively constrain deformation of the concrete column and improve compression bearing capacity, shear bearing capacity, and seismic performance of the concrete column. Eigenvalue and prestressing force level of steel plate hoop influence its shear coefficient and poor force transfer performance at the bonding surface will result in a bad overall stress state of the reinforced specimen $[12,13]$.

Shin and Andrawes [21] used a thermo-sensitive shapememory alloy hoop upon pier column on a bridge under seismic damage. Theoretical and comparative studies were conducted, and a calculation model was explored, describing hysteresis characteristics and damage state of the reinforced column. Guo et al. [23] fabricated 16 circular concrete columns using prestressed steel strand tensile anchorage technology and found reinforced specimens were significantly improved in yield loading, ultimate loading, displacement ductility, and accumulated energy consumption. Thereby, the prestressed steel strand reinforcement technology is proved to be active, nondestructive, and highly efficient with board promotion and application value.

Concrete column reinforcement using prestressed steel strip can delay cracking and improve the seismic performance of the component. Meanwhile, the shear bearing capacity, axial compression bearing capacity, and deformation performance can also be improved. However, considerable disadvantages for the method are found: (1) each steel strip or steel plate hoop separately applies prestressing force, and a great difference exists between steel strips in prestressing force; (2) a concrete column between steel strips is exposed out without prestressing force constraint from steel strips, which will possibly result in early-stage cracking; (3) the concrete at the original column cover in contact part between steel strips is under three-way stress state, while exposed concrete is still under two-way stress state, so the design and calculation are complicated; (4) prestressing force of steel strips is limited; and (5) joints of steel strips are exposed, which present an ugly appearance.

In a word, to the traditional reinforced method of the concrete column, there are many shortcomings including the following: (1) it is necessary to produce a certain degree of damage to the reinforced concrete columns; (2) string reinforcement construction cannot be carried out online; (3) the existence of the torque interface prevents the new and old materials from working in sync, and the new material has stress hysteresis; and (4) the superior reinforcement effect is not obvious. New reinforcement methods are urgently needed.

Circular concrete column reinforcement using a twoway prestressed semicircular steel plate is a new-type 

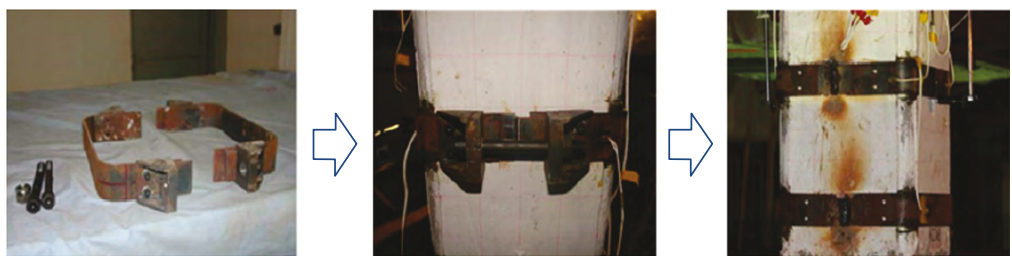

(a) Steel hoop of rectangular cross-section
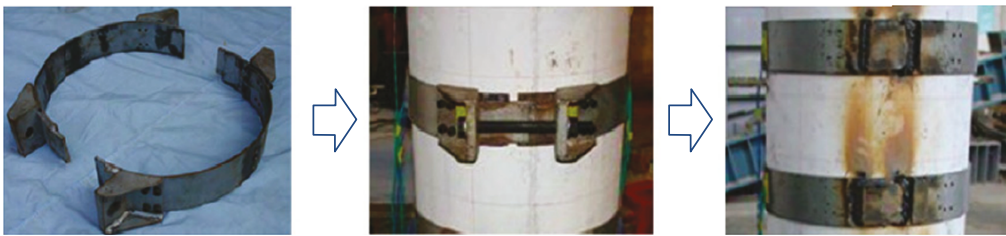

(b) Steel hoop of circular cross-section

Figure 2: The reinforcement method of improved prestressed steel hoop.

reinforcement method invented by the author. After the reinforcement of the concrete column using the two-way prestressed semicircular steel plate, axial prestressing force unloads part of the axial force which ought to be handed by the concrete. Meanwhile, the confining pressure from prestressing force can be witnessed in the circumferential direction. The reinforcement process does not damage the structure of the original concrete column or degrade its bearing capacity. The adjustment of axial and circumferential prestressing forces of the semicircular steel plate can guarantee the synchronous stress-bearing process of the original structure and reinforced structure. Moreover, the stress is transformed from the passive three-way stress state to the active three-way stress state so that the deformation performance of the core concrete is improved. As a result, the two-way prestressing reinforcement method benefits column strength, rigidity, and ductility in considerable aspects. Furthermore, the new-type reinforcement method is simple and convenient for the construction, demonstrating favorable engineering application prospect.

As a new-type structural system, research is found regarding prestressed semicircular steel plate-reinforced concrete columns. Therefore, based on a unified strength theory, axial compression mechanism of the short concrete column in this new-type structural system was analyzed. The substitution effect of vertical prestressing stress on the concrete column is considered. The multiple constraint effects of two-way prestressing configuration, semicircular steel plate, and stirrup on the concrete are combined and considered. Thereby, the computational formula of axial compression bearing the capacity of the reinforced short prestressed semicircular concrete column was derived. Meanwhile, the calculated results obtained through the computational formula were compared with test results in $[24,25]$ to verify the reliability of the formulas.

\section{Basis of the Strength Theory}

Tresca-Mohr-Coulomb-Schmid is a single shear stress theory with a maximum shear stress theory only considering one maximum principal shear force and the corresponding normal stress on its action surface. To consider the influence of intermediate principal shear stress $\sigma_{2}$ on yield, Yu et al. [26, 27] put forward dual shear stress yield criterion in 1990. The expression of the generalized dual shear stress theory is as follows:

$$
\begin{array}{ll}
\sigma=\tau_{13}+\tau_{12}+\beta \cdot\left(\sigma_{13}+\sigma_{12}\right)=C, & \sigma \geq \sigma^{\prime}, \\
\sigma=\tau_{12}+\tau_{23}+\beta \cdot\left(\sigma_{13}+\sigma_{23}\right)=C, & \sigma<\sigma^{\prime},
\end{array}
$$

where $\tau_{13}$ is the maximum principal shear stress; $\tau_{12}$ and $\tau_{23}$ are the other two principal shear stresses, where the greater one is the intermediate principal shear stress and the smaller one is the smallest principal shear stress; $\sigma_{13}, \sigma_{23}$, and $\sigma_{12}$ are normal stresses on $\tau_{13}, \tau_{23}$, and $\tau_{12}$ action surfaces; $\beta$ is the influence parameter of dodecahedral normal stress on breaking strength; and $C$ is the parameter reflecting material strength. Through the simplification of (1), a concise generalized dual shear stress criterion which is quite similar to the Mohr-Coulomb criterion can be obtained as follows [27]:

$$
\begin{aligned}
\sigma_{2} & \leq \frac{\sigma_{1}+\alpha \cdot \sigma_{3}}{1+\alpha}, \\
\sigma & =\sigma_{1}-\frac{\alpha}{1+\theta}\left(\theta \cdot \sigma_{2}+\sigma_{3}\right)=\sigma_{\mathrm{ts}}, \\
\sigma_{2} & \geq \frac{\sigma_{1}+\alpha \cdot \sigma_{3}}{1+\alpha}, \\
\sigma^{\prime} & =\frac{1}{1+\theta}\left(\sigma_{1}+\theta \cdot \sigma_{2}\right)-\alpha \cdot \sigma_{3}=\sigma_{\mathrm{ts}},
\end{aligned}
$$

where $\theta=\left((1+\alpha) \cdot \tau_{\mathrm{s}}-\sigma_{\mathrm{ts}}\right) /\left(\sigma_{\mathrm{ts}}-\tau_{\mathrm{s}}\right)=(1+\alpha-B) /(B-1)$, $\alpha=\sigma_{\mathrm{ts}} / \sigma_{\mathrm{cs}}, B=\sigma_{\mathrm{ts}} / \tau_{\mathrm{s}}, \sigma$ and $\sigma^{\prime}$ are the theoretical functions of the principal stress strength, $\sigma_{1}, \sigma_{2}$, and $\sigma_{3}$ are the major, secondary, and third principal stresses, respectively, and tensile stress is positive while compressive stress is negative, $\alpha$ is the material tensile-compressive stress ratio, $\sigma_{\mathrm{ts}}, \sigma_{\mathrm{cs}}$, and $\tau_{\mathrm{s}}$ are the ultimate tensile yield strength, ultimate compressive yield strength, and ultimate shear yield strength of 
the material, respectively, $\theta$ is the weighing parameter which reflects influence intermediate shear stress and normal stress on corresponding action surface on material yield or failure, $0 \leq \theta \leq 1$, and $B$ is the shear stress coefficient.

\section{New Concrete Column Reinforcement Method}

3.1. The Idea and Method of the New Method. "Online nondestructive reinforcement of circular concrete column using Two-Way prestressed semicircular steel plate" gained a national patent for the invention in China in 2018 (patent number ZL2016 10897810.0 ). Its conception is as such: axial and circumferential prestressing forces are applied to the concrete column through two tailor-made semicircular steel plates, and circumferential prestressing force is applied to the concrete column while the partial load of the original concrete column is released. Reinforced segment of the reinforced concrete column is divided into the upper reinforced segment, the axial prestressing force jacking segment, and the lower reinforced segment. Semicircular steel plates with flanges at four sides are installed at the upper and lower reinforced segments. The semicircular steel plate is drawn and fastened through the axial flange on the semicircular steel plate to form a steel cylinder, and circumferential prestressing force is applied to the upper and lower reinforced segments of the concrete column so as to realize reinforcement; in axial prestressing force jacking segment, axial prestressing force is applied to the upper and lower steel cylinders consisting of the semicircular steel plate through screw plugged in the circumferential flange of the semicircular steel plate and the rotary-type nut on the screw. On this basis, partial unloading is carried out for the concrete column and the installation model is shown in Figure 3.

After the reinforcement on the concrete column, the decoration layer is casted on the external surfaces of the upper and lower steel cylinders. A reinforcement framework is installed in the decoration layer, consisting of a vertical plate and annular stirrup. One end of the vertical plate is welded on the surface of the semicircular steel plate while the other end is welded with the annular stirrup. Finally, a template is erected outside the welded annular stirrup and a fresh concrete is casted to realize the reinforcement of the concrete column using a prestressed semicircular steel plate. The schematic diagram is shown in Figure 4.

3.2. The Application of the New Reinforcement Method. The application of the new reinforcing method of the concrete column using a two-way prestressed semicircular steel plate is as follows: (1) in the case of emergency, the concrete column shall be reinforced without damage, (2) there is on-line reinforcement of the round-section concrete piers of expressway and high-speed railway bridges, (3) the reinforcement of the reinforced concrete column stated above is also applicable to the reinforcement of the concrete pile which can be dug, and (4) it is necessary to strengthen the columns which can greatly improve the bearing capacity of concrete columns.

\subsection{Innovations of the New Reinforcement Method}

(1) The circular concrete column reinforcement method using the two-way prestressed semicircular steel plate features adjustable prestressing force, no need to open holes or embed steel bars on the concrete column as this will damage the concrete column, and this method does not affect online application of the structural column.

(2) Existence of prestressing force guarantees synchronous stress bearing between the original column and the reinforced structure without gradient failure.

(3) Two-way prestressing force is applied to the original concrete column using a semicircular steel plate, which not only conducts partial unloading of the original column but also transforms the two-way stress state of the original concrete into an active three-way stress state. Compressive strength of concrete is improved, and the concrete inside the semicircular steel cylinder can effectively prevent local buckling of the semicircular steel plate.

(4) The technical effect brought by the application of two-way prestressing force is not a simple superposition of two, and the effect is more than expected. Through calculation, the semicircular steel plate is used to wrap the column outside to form a circular steel cylinder so as to reinforce the column, and the bearing capacity is about $1.75-4.30$ times as that before reinforcement,

(5) When two-way prestressing force is used to reinforce the concrete column, circumferential prestressing force reasonably matches axial prestressing force so that the bearing capacity of the concrete column after reinforcement reaches the optimal value.

(6) Circumferential prestressing force does not exceed the design tensile strength value of the semicircular steel plate to ensure the same reliability between designed circumferential prestressed circular steel cylinder and original concrete column.

\section{Axial Bearing Capacity of Reinforced Short Concrete Column}

4.1. Overall Stress Analysis. Stress-bearing situation of the prestressed semicircular steel plate-reinforced concrete column is very complicated under the axial load. In the horizontal direction, the core concrete is constrained by horizontal prestressing force from stirrup and semicircular steel plate, demonstrating its active three-way stress state. In the axial direction, the axial prestressing force is applied to the prestressed semicircular steel plate so that partial loading on the original concrete column is transferred. The steel cylinder formed by the semicircular steel plate is thus under three-way loading, namely, axial compression, circumferential tension, and radial compression (prestressing force). Besides, the stirrups of the original column are under tensile force while 


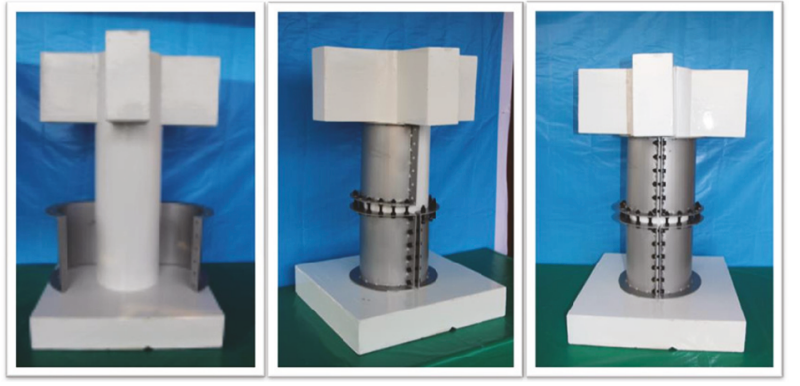

FIgURE 3: The model of prestressed reinforcement column.

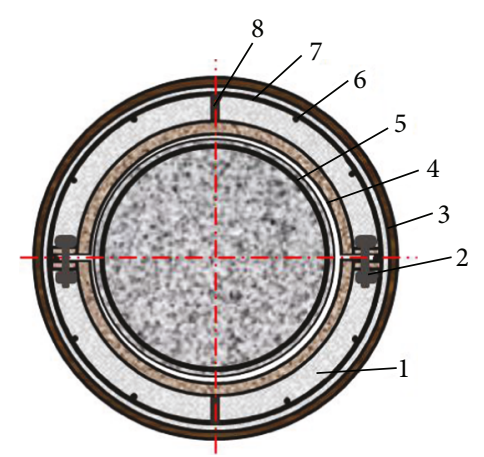

1. Post-poured protective concrete

5. Reinforced columnconcrete

2. Bolts

3. Template

4. Semicircular steel plate

6. Structural vertical tendons

7. Ring structure stirrup

8. Stud or riser

FIGURE 4: Concrete column strengthened with prestressed semicircular steel plate.

longitudinal reinforcement is under compression force. The stress analysis diagram of the concrete column after reinforcement is shown in Figure 5.

As shown in Figure 5, the thickness of the semicircular steel plate is $t$, confining the pressure of the semicircular steel plate on the concrete column is $\sigma_{\mathrm{r} 1}$, and stress bearing of the semicircular steel plate is shown in Figures 5(b) and 5(c). As axial prestressing force is also applied to prestressing force jacking segment of the semicircular steel plate, it can be assumed that axial prestressing force, radial compressive force, and circumferential tensile stress of the semicircular steel plate are $\sigma_{\mathrm{z}}, \sigma_{\mathrm{r} 1}$ and $\sigma_{\theta}$, respectively, and then

$$
\begin{aligned}
\sigma_{\mathrm{z}} & =\frac{N_{1}}{A_{\mathrm{s} 1}}, \\
\sigma_{\mathrm{r} 1} & =-\sigma_{\mathrm{r}}, \\
\sigma_{\theta} & =\frac{\sigma_{\mathrm{r} 1} \cdot d}{2 \cdot t},
\end{aligned}
$$

where $N_{1}$ is the axial prestressing force applied to the semicircular steel plate in the semicircular steel plate-reinforced concrete column, $A_{\mathrm{s} 1}$ is the sectional area of the semicircular

steel plate, approximating to $d \cdot \pi \cdot t, \sigma_{\mathrm{r}}$ is the lateral constraint stress generated by the semicircular steel plate cylinder to the concrete, $d$ is the external diameter of the concrete column, namely, the inner diameter of the semicircular steel plate. The steel plate used by the semicircular steel plate-reinforced concrete column in engineering and the test is usually of very thin wall, all satisfying $d / t \geqq 20$, so it can be regarded as the thin-wall steel plate; namely, $\left|\sigma_{r}\right| \ll \sigma_{\theta}, \sigma_{\theta}>$ $\sigma_{z}$ can be assumed; then the principal stresses of thin-wall steel tube are

$$
\begin{aligned}
& \sigma_{1}=\sigma_{\theta}, \\
& \sigma_{2}=\sigma_{\mathrm{r} 1}, \\
& \sigma_{3}=\sigma_{\mathrm{z}} .
\end{aligned}
$$

Equation (4) is substituted into (2a); the following can be obtained:

$$
\frac{\sigma_{1}+\alpha \cdot \sigma_{3}}{1+\alpha}=\frac{\sigma_{\theta}+\alpha \cdot \sigma_{\mathrm{z}}}{1+\alpha}>0>\sigma_{2}=\sigma_{\mathrm{r} 1} .
$$

Equation (4) is substituted into the equation on the right of (2a); after simplification, the following can be obtained:

$$
\sigma_{\mathrm{z}}=-\frac{1+\theta}{\alpha}\left[\sigma_{\mathrm{ts}}-\left(\frac{d}{2 t}+\frac{\alpha \cdot \theta}{1+\theta}\right) \cdot \sigma_{\mathrm{r} 1}\right] .
$$

4.2. Stirrup Stress. Stress bearing of the stirrup and core concrete inside the concrete column is shown in Figure 5(f). When the spacing of continuous spiral stirrups configured in the compressed column or individual octagonal stirrups is small along the column axis, the effective constraint will be generated to the core concrete they enclose. As acting force applied by the semicircular steel plate to stirrups inside the column through the concrete cover is $\sigma_{\mathrm{r} 1}$, constraint stress can also be expressed as the following according to force balance in Figure 5(f) [28]:

$$
\sigma_{\mathrm{r} 2}=\frac{2 f_{\mathrm{yt}} \cdot A_{\mathrm{s} 2}}{s \cdot d_{\mathrm{cor}}}+\sigma_{\mathrm{r} 1}
$$

where $\sigma_{\mathrm{r} 2}$ is the constraint stress generated by the stirrup to the core concrete, $f_{\mathrm{yt}}$ is the stirrup yield strength, $d_{\text {cor }}$ is the (inner edge) diameter of the core concrete, $A_{\mathrm{s} 2}$ is the sectional area of the single stirrup, and $s$ is the longitudinal spacing of stirrups.

\subsection{Concrete Bearing Capacity}

4.3.1. The Bearing Capacity of Protective Layer Concrete. The concrete cover inside the semicircular steel plate outside stirrups bears outside inward acting force $\sigma_{\mathrm{r} 1}$ from steel cylinder constraint. Meanwhile, due to the acting force applied to outward stirrup expansion to the concrete cover, this force can also be assumed as $\sigma_{\mathrm{r} 1}$ as shown in Figure 5(e). The concrete cover is equivalent to a stress-bearing cylinder, inner radius and outer radius are $d_{\text {cor }} / 2$ and $d / 2$, respectively, and the cylinder bears the inner pressure $\sigma_{\mathrm{r} 1}$ and the outer pressure $\sigma_{\mathrm{r} 1}$. 


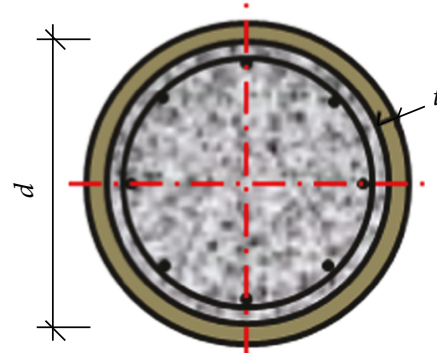

(a)

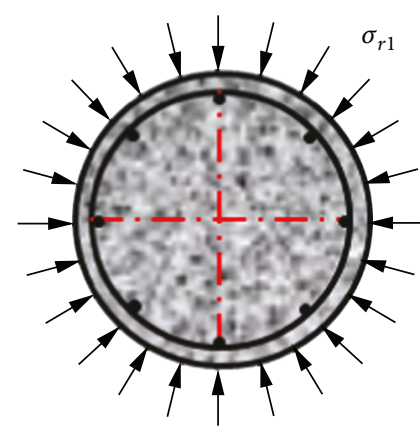

(d)

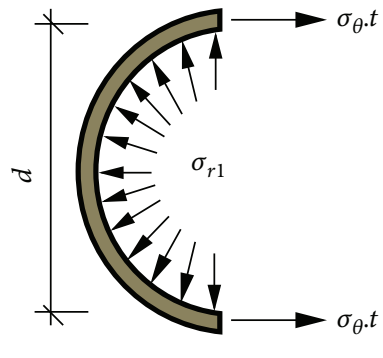

(b)

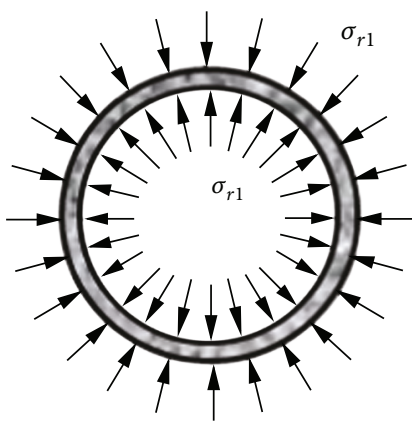

(e)

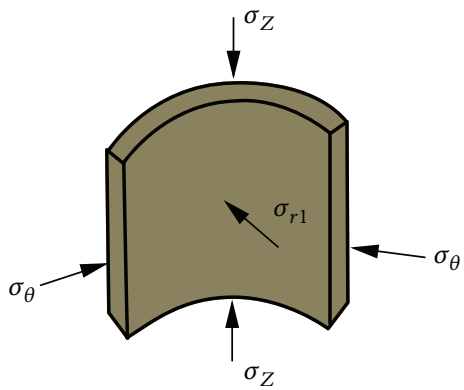

(c)

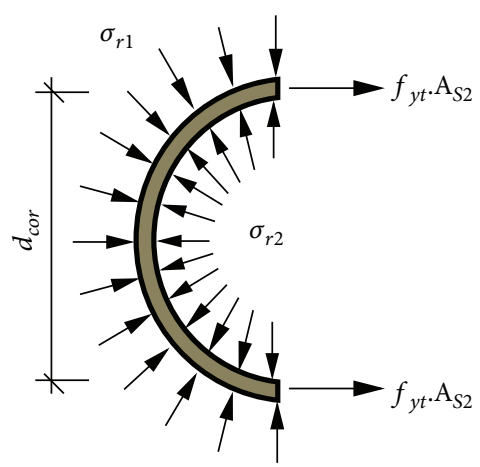

(f)

FIgURE 5: Semicircle steel shield and the force of columns.

Its stress distribution should be axisymmetric, and the expression is as follows [29]:

$$
\sigma_{\mathrm{r}}=\sigma_{\theta}=\sigma_{\mathrm{r} 1} .
$$

The compressive strength $f_{c 1}^{\prime}$ of the outer-layer concrete is obtained as follows:

$$
f_{\mathrm{cl}}^{\prime}=f_{\mathrm{cy}}+k \sigma_{\mathrm{r} 1},
$$

where $k$ is the stress coefficient of concrete and can be taken as $4.0, f_{\text {cy }}$ is the uniaxial compressive strength of the concrete, and for the circular section column, uniaxial compressive strength of cylinder is taken. Then axial compression bearing capacity $\mathrm{N}_{2}$ of outer-layer concrete is as follows:

$$
N_{2}=\left(f_{\mathrm{cy}}+k \sigma_{\mathrm{r} 1}\right) A_{\mathrm{cl}} \text {, }
$$

where $A_{\mathrm{cl}}$ is the sectional area of outer-layer concrete, $A_{\mathrm{cl}}=\pi\left[(d / 2)^{2}-\left(d_{\mathrm{cor}} / 2\right)^{2}\right]$.

4.3.2. The Bearing Capacity of Core Concrete in Stirrup. The core concrete bears dual constraint effects of the semicircular steel plate cylinder and stirrup [30-32], so it is under a three-way stress state. The computational formula of the axial compressive strength of the concrete $f_{c}^{\prime}$ under the three-way stress state derived by [33] through unified strength theory is adopted $f_{\mathrm{c}}^{\prime}=f_{\mathrm{cy}}+k \sigma_{\mathrm{r} 2}, \sigma_{\mathrm{r} 2}$ is the binding force on the core concrete. The bearing capacity of the core concrete is as follows:

$$
N_{3}=\left(f_{\mathrm{cy}}+k \cdot \frac{2 f_{\mathrm{yt}} A_{\mathrm{s} 2}}{s \cdot d_{\mathrm{cor}}}+k \sigma_{\mathrm{r} 1}\right) A_{\mathrm{cor}},
$$

where $A_{\text {cor }}$ is the sectional area of the core concrete, $A_{\text {cor }}=$ $\pi\left(d_{\text {cor }} / 2\right)^{2}$.

4.4. Bearing Capacity of Longitudinal Reinforcement. Longitudinal reinforcement goes through yield when the concrete column after reinforcement reaches ultimate axial compression bearing capacity, so its axial compression bearing capacity $N_{4}$ is as follows:

$$
N_{4}=f_{\mathrm{ys}} A_{\mathrm{s} 3}
$$

where $f_{\mathrm{ys}}$ is the yield strength of longitudinal reinforcement and $A_{\mathrm{s} 3}$ is the sectional area of longitudinal reinforcement.

4.5. Unified Solution of Axial Bearing Capacity. The bearing capacity $\boldsymbol{N}$ of the concrete column reinforced by the two-way prestressed semicircular steel plate consists of bearing capacities provided by four parts: steel tube, outer-layer concrete, core concrete, and longitudinal reinforcement, namely,

$$
N=N_{1}+N_{2}+N_{3}+N_{4} .
$$

Equations (3), (6), (10), (11), and (12) are substituted into (13), and after organization, the unified solution of the axial 
compression bearing capacity of the concrete column reinforced by the two-way prestressed semicircular steel plate is obtained as follows:

$$
\begin{aligned}
N= & -\frac{1+\theta}{\alpha} \sigma_{\mathrm{ts}} A_{\mathrm{s} 1}+f_{\mathrm{cy}}\left(A_{\mathrm{c} 1}+A_{\mathrm{cor}}\right)+k \frac{2 f_{\mathrm{yt}} A_{\mathrm{s} 2}}{s \cdot d_{\mathrm{cor}}} A_{\mathrm{cor}}+f_{\mathrm{ys}} A_{\mathrm{s} 3} \\
& +\left[k \cdot\left(A_{\mathrm{c} 1}+A_{\mathrm{cor}}\right)+\frac{1+\theta}{\alpha}\left(\frac{d}{2 t}+\frac{\alpha \theta}{1+\theta}\right) A_{\mathrm{s} 1}\right] \sigma_{\mathrm{r} 1} .
\end{aligned}
$$

When $N_{1}=0$, the above equation is transformed into

$N=f_{\mathrm{cy}}\left(A_{\mathrm{c} 1}+A_{\mathrm{cor}}\right)+k \frac{2 f_{\mathrm{yt}} A_{\mathrm{s} 2}}{s \cdot d_{\mathrm{cor}}} A_{\mathrm{cor}}+f_{\mathrm{ys}} A_{\mathrm{s} 3}+k\left(A_{\mathrm{c} 1}+A_{\mathrm{cor}}\right) \sigma_{\mathrm{r} 1}$.

Bearing capacity is the function of lateral constraint stress $\sigma_{\mathrm{r} 1}$, as $\sigma_{\mathrm{ts}}=f_{\mathrm{y}}$ when circumferential tensile stress of thin-wall steel cylinder reaches limiting value, namely, its lateral constraint force reaches limiting value, and the following can be obtained through (3), $\sigma_{\theta}=f_{\mathrm{y}}$,

$$
\sigma_{\mathrm{r} 1}=\frac{2 \cdot t \cdot f_{\mathrm{y}}}{d}
$$

where $f_{\mathrm{y}}$ is the yield strength of the semicircular steel plate. Limiting value $N_{\mathrm{u}}$ of axial compression bearing capacity can be obtained by substituting (16) into (14),

$$
\begin{aligned}
N_{\mathrm{u}}= & -\frac{1+\theta}{\alpha} f_{\mathrm{y}} A_{\mathrm{s} 1}+f_{\mathrm{cy}}\left(A_{\mathrm{cl}}+A_{\mathrm{cor}}\right)+k \frac{2 f_{\mathrm{yt}} A_{\mathrm{s} 2}}{s \cdot d_{\mathrm{cor}}} A_{\mathrm{cor}} \\
& +f_{\mathrm{ys}} A_{\mathrm{s} 3}+\left[k A_{\mathrm{c} 1} k A_{\mathrm{cor}}+\frac{1+\theta}{\alpha}\left(\frac{d}{2 t}+\frac{\alpha \theta}{1+\theta}\right) A_{\mathrm{s} 1}\right] \frac{2 t f_{\mathrm{y}}}{d} .
\end{aligned}
$$

When $A_{\mathrm{s} 2}=0$ and $A_{\mathrm{s} 3}=0,(17)$ is reduced to the computational formula of the axial compression bearing capacity of the ordinary short circular concrete-filled steel tube column,

$$
\begin{aligned}
N_{\mathrm{u}}= & -\frac{1+\theta}{\alpha} f_{\mathrm{y}} A_{\mathrm{s} 1}+f_{\mathrm{cy}}\left(A_{\mathrm{c} 1}+A_{\mathrm{cor}}\right) \\
& +\left[k\left(A_{\mathrm{c} 1}+A_{\mathrm{cor}}\right)+\frac{1+\theta}{\alpha}\left(\frac{d}{2 t}+\frac{\alpha \cdot \theta}{1+\theta}\right) A_{\mathrm{s} 1}\right] \frac{2 \cdot t \cdot f_{\mathrm{y}}}{d} \\
= & 2 \cdot b \cdot \pi \cdot t^{2} \cdot f_{\mathrm{y}}+\left(f_{\mathrm{cy}}+k \frac{2 \cdot t \cdot f_{\mathrm{y}}}{d}\right) A_{\mathrm{c}}
\end{aligned}
$$

where $A_{c}$ is the sectional area of the core concrete of the ordinary short circular concrete-filled steel tube column, $A_{\mathrm{c}}=A_{\mathrm{cl}}+A_{\text {cor }}$.

\section{Formula Check and Computation of Reinforcement Effect}

5.1. Formula Check. As the new method has just obtained a national patent for the invention in China, the corresponding test has not been implemented yet. In order to verify the correctness of the computational formula, vertical prestressing force can be assumed to be zero firstly, and verification will be implemented according to test results of the concrete-filled steel tube column. Therefore, this paper has used (15) to calculate bearing capacities of 7 circular concrete-filled steel tube columns in $[24,25]$. At the time, $N_{1}=0, A_{\mathrm{s} 2}=0$, and $A_{\mathrm{s} 3}=0$, in Table 1 ; the compressive strength of concrete prism is $f_{\mathrm{c}}$, and the yield strength of the steel plate is $f_{\mathrm{y}}, D$ represents the diameter of the concrete column, $t$ represents the thickness of steel tube wall, and $l$ represents the height of column, and the specific calculated data are shown in Table 1 . Results show that the mean value between calculated bearing capacity value in [24] by (15) and test value is 0.9975 . The mean value between calculated bearing capacity value in [25] by (15) and test value is 0.9528 , so theoretically, calculated values accord with test values very well. This indicates that the formula proposed in this paper can be applied to the theoretical computation of the ultimate bearing capacity of the concrete column reinforced by the prestressed semicircular steel plate.

5.2. Example Verification and Reinforcement Effect of TwoWay Prestressing Force. In order to compare reinforcement effects under several circumstances, several reinforcement specimens are prepared according to specific requirements in engineering practice. The corresponding calculations are carried out to verify the reinforcing results.

5.2.1. Original Column and Its Ultimate Bearing Capacity (Scheme 1). A multilayer frame structural column, with diameter $d=500 \mathrm{~mm}$, is designed according to the short column under axial compression. The design axial force value is $N=3900 \mathrm{kN}$, the calculated column length is $l_{0}=$ $6 \mathrm{~m}$, and its slenderness ratio is 12 . The concrete is C30 with $f_{\mathrm{c}}=14.3 \mathrm{~N} / \mathrm{mm}^{2}$ and $f_{\mathrm{cy}}=20.1 \mathrm{~N} / \mathrm{mm}^{2}$; longitudinal reinforcement $f_{\mathrm{y}}^{\prime}=360 \mathrm{~N} / \mathrm{mm}^{2}$ and $f_{\mathrm{ys}}=400 \mathrm{~N} / \mathrm{mm}^{2}$; the stirrup $f_{\mathrm{yv}}=300 \mathrm{~N} / \mathrm{mm}^{2}$ and $f_{y t}=335 \mathrm{~N} / \mathrm{mm}^{2} ; A_{\mathrm{s} 2}=113.1 \mathrm{~mm}^{2}$, longitudinal reinforcement is of $6 \Phi 20$ with $A_{\mathrm{s} 3}=1884 \mathrm{~mm}^{2}$, diameter of core section of the column is $d_{\text {cor }}=440 \mathrm{~mm}$, and core sectional area is $A_{\text {cor }}=152053 \mathrm{~mm}^{2}$. According to the following formula:

$$
N_{\mathrm{uo}} \leq 0.9\left(f_{\mathrm{cy}} \cdot A_{\mathrm{cor}}+f_{\mathrm{ys}} \cdot A_{\mathrm{s} 3}+2 \alpha_{0} f_{\mathrm{yt}} A_{\mathrm{sso}}\right)
$$

where $\alpha_{0}$ is a coefficient which can be taken as $\alpha_{0}=1, A_{\text {sso }}$ is the converted sectional area of the welded annular stirrup, $s$ is the longitudinal spacing of stirrups, and it can be calculated as $s=60 \mathrm{~mm}$ according to the design bearing capacity of the column. Yield bearing capacity $N_{\text {uo }}=4999.281 \mathrm{kN}$ of the circular column can be obtained by substituting concrete data into Formula (19).

5.2.2. The Concrete Column Is Reinforced through Section Expansion Method Using Ordinary Embedded Steel Bar (Scheme 2). The outer diameter of the column is reinforced to $d=700 \mathrm{~mm}$. Holes are opened on the original column which is then implanted with 12 radial HRB335 $\Phi 12$ reinforcements. HRB335 $\Phi 12$ annular stirrups are welded at the 
TABLE 1: The calculation value of the formula is compared with that of the literature test.

\begin{tabular}{|c|c|c|c|c|c|c|c|}
\hline \multirow[b]{2}{*}{ Data sources } & \multirow[b]{2}{*}{$D \times t \times l(\mathrm{~mm} \times \mathrm{mm} \times \mathrm{mm})$} & \multirow[b]{2}{*}{$f_{\mathrm{c}}(\mathrm{MPa})$} & \multicolumn{5}{|c|}{ Ultimate bearing capacity $(\mathrm{kN})$} \\
\hline & & & $f_{\mathrm{y}}(\mathrm{MPa})$ & Testing value & $\begin{array}{l}\text { Calculated value } \\
\text { of literature }\end{array}$ & $\begin{array}{l}\text { Calculated value } \\
\text { of this paper }\end{array}$ & Error $(\%)$ \\
\hline \multirow{3}{*}{ Literature [24] } & $90 \times 1.0 \times 300$ & 28.80 & 328.95 & 348.80 & 333.86 & 339.12 & 2.8 \\
\hline & $90 \times 1.2 \times 300$ & 28.80 & 328.95 & 360.50 & 363.01 & 358.64 & 0.5 \\
\hline & $90 \times 1.5 \times 300$ & 28.80 & 328.95 & 390.70 & 406.22 & 399.52 & 2.3 \\
\hline \multirow{4}{*}{ Literature [25] } & $125 \times 1.0 \times 438$ & 84.70 & 232 & 1257 & 1162 & 1189.89 & 5.3 \\
\hline & $133 \times 3.5 \times 465$ & 74.50 & 352 & 1983 & 1900 & 1903.54 & 4.0 \\
\hline & $127 \times 7.0 \times 465$ & 84.70 & 429 & 3379 & 2883 & 3120.36 & 7.7 \\
\hline & $108 \times 4.5 \times 378$ & 77.40 & 358 & 1544 & 1537 & 1564.32 & 1.3 \\
\hline
\end{tabular}

ends of the radial reinforcements, stirrup spacing can be expanded to $s_{1}=200 \mathrm{~mm}, 12$ HRB400 $\$ 12$ longitudinal reinforcements are used for reinforcement, later added concrete is also $\mathrm{C} 30$, and reinforced sectional structure is shown in Figure 6.

The bearing capacity of the original concrete column is solved according to (19). $N_{\mathrm{u}}^{\prime}=4320.332(\mathrm{kN})$ is calculated for reinforced reinforcement and concrete according to the ordinary stirrup-reinforced concrete column, and $N_{\mathrm{u} 1}=$ $N_{\text {uo }}+N_{\mathrm{u}}^{\prime}=4999.281 \mathrm{kN}+4320.332 \mathrm{kN}=9319.613 \mathrm{kN}$.

5.2.3. Original Column Is Reinforced Using the Invented Reinforcement Method. The schematic diagram of circular cross-section reinforced by the prestressed semicircular steel plate and embedded steel bar is shown in Figure 4. Radial reinforcement and stirrup are still $\Phi 12$, and longitudinal reinforcement is HRB400\$12. No requirement is posed for the quantity of embedded steel bars outside the semicircular steel plate which are only used for construction, and their bearing capacities are not taken into consideration. $t=10 \mathrm{~mm}$ Q235 steel plate is selected as the semicircular steel plate, and its yield strength is $f_{\mathrm{y}}=235 \mathrm{~N} / \mathrm{mm}^{2}$.

(1) The Circular Prestress Makes the Stirrup in the Original Column Unstressed (Scheme 3). At the time, $N_{1}=0$ and $\sigma_{r 2}=\sigma_{r 1}$. The following can be obtained by substituting concrete data into (15), $N=8711.991(\mathrm{kN})$. The bearing capacity of the reinforced column increases by $74.26 \%$ when compared with that of the original column. Prestressing force of the semicircular steel plate offsets stress borne by the stirrup in the original column. After the reinforced column bears stress again, stirrup in the original column will further bear tensile force, and this is equivalent to adding a layer of stirrups equal to those added to the original column.

(2) The Circular Prestress Makes Semicircular Steel Reach the Yield Strength (Scheme 4). The yield strength of the semicircular steel plate is $f_{\mathrm{y}}=235 \mathrm{~N} / \mathrm{mm}^{2} . \sigma_{\mathrm{r} 1}=9.4 \mathrm{~N} / \mathrm{mm}^{2}$ can be known from (16). Concrete data are substituted into (15); $N=17824.826(\mathrm{kN})$. The bearing capacity of the column only applied with circumferential prestressing force increases

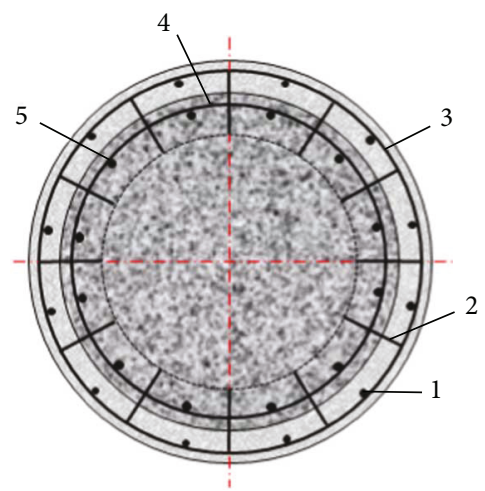

1. Reinforce the longitudinal reinforcement

2. Radiation tendons implanted in the original column

3. Post-welding stirrup

4. Stirrup of the original column

5. Longitudinal reinforcement of the original column

Figure 6: New column parameter diagram.

by $256.55 \%$ when compared with that of the original column. Compared with Scheme 1, the bearing capacity of the reinforced column in Scheme 4 increases to 3.57 times of that of the original column, completely because circumferential prestressing force is increased.

(3) Both Cyclic Prestress and Axial Prestress Make Semicircular Steel Plate Reach Yield Strength (Scheme 5). The concrete column is reinforced after prestressed semicircular steel plates gather up, and the steel cylinder formed by the semicircular steel plate will probably go through instability. The thickness of the steel plate is $10 \mathrm{~mm}$. Inner diameter, outer diameter, sectional area, sectional inertia moment, and axial radius of inertia of compression bar section to the concrete column are $d=500 \mathrm{~mm}, D=520 \mathrm{~mm}, 15,700 \mathrm{~mm}^{2}, I=520,855,350 \mathrm{~mm}^{2}$ and $r=182.14 \mathrm{~mm}$, respectively, for the steel cylinder. On this basis, its flexibility can be obtained as $\lambda=32.94$. Limiting the value of flexibility of compression bar fabricated by Q235 steel is as follows: $\lambda_{\mathrm{p}}=\pi \cdot \sqrt{E / \sigma_{\mathrm{P}}}$, where $E$ is the steel elasticity modulus, $E=2.06 \times 10^{5}, \sigma_{\mathrm{P}}$ is the proportional limit of steel material, $\sigma_{\mathrm{P}}=200 \mathrm{MPa}, \lambda_{\mathrm{p}}=100 \mathrm{can}$ be obtained after substituting concrete data, so $\lambda<\lambda_{\mathrm{p}}$, and compression bar 
fabricated by steel material will not go through critical instability. $f_{\mathrm{y}}=235 \mathrm{~N} / \mathrm{mm}^{2}$ taken, $N_{1}=A_{\mathrm{s} 1} \times f_{y}=15700 \times 235$ $=3689.5 \mathrm{kN}$. The design bearing capacity of the original column can be calculated through (19) as $N_{10}=3973.669 \mathrm{kN}$. Therefore, the following can be taken: $N_{\mathrm{ul}}=N_{1}+N$, where $N_{1}$ is the bearing capacity of the steel cylinder when it reaches yield strength in the axial direction of the concrete column, $N$ is the bearing capacity of reinforced column obtained when the semicircular steel plate reaches yield strength without axial application of prestressing force to the concrete column by the two-way prestressed semicircular steel plate but with the circumferential application of prestressing force. $N=17824.826 \mathrm{kN}$ can be obtained from the previous section, so $N_{\mathrm{u} 1}=21514.326 \mathrm{kN}$. The bearing capacity of the reinforced column increases by $330.35 \%$ when compared with that of the original column. After application of two-way prestressing force for reinforcement, the bearing capacity of the reinforced column is improved to 4.3 times of that of the original column.

\subsection{Analysis on Reinforcement Mechanism and Parameter} Variation. The working mechanism of the two-way prestressed semicircular steel plate for strengthening concrete column is summarized as follows: (1) the round steel pipe composed of the prestressed steel plate is equivalent to a dense row of stirrup and bears shear force, (2) the round steel pipe can restrict the lateral expansion of the concrete, make the core concrete in the active three-way stress state, and improve the bearing capacity and ductility of the column, (3) the round steel pipe can restrain the expansion of longitudinal steel lap joints and indirectly improve the bearing capacity of reinforced concrete columns, (4) the axial prestress is applied to semicircular steel plate to enable partial unloading of the original column, (5) the round steel pipe can prevent the concrete protective layer from falling off and increase the lateral support of longitudinal steel bar, (6) the technical effect of applying two-way prestress is not the simple superposition of the two. It is calculated that the capacity of concrete columns can be increased to 1.75-4.30 times of that before reinforcement by the reinforcement method in this paper.

It can be seen from (14) that $N=\sum_{i=1}^{4} N_{i}=\sum_{i=1}^{4} a_{i}+\sum_{i=1}^{4}$ $b_{i} \cdot \sigma_{r 1}$ is a linear function of $\sigma_{\mathrm{r} 1}$; therefore, the bearing capacity of the reinforced column is linearly related to the size of the two-way prestress after the column and semicircular steel plate is selected. The upper limit of cyclic prestress is the yield strength of the semicircular steel plate, and the upper limit of axial prestress is the actual force of the concrete column when it is reinforced.

\section{Conclusions}

(1) By utilizing the unified strength theory, the computational formula of the axial compression bearing capacity of the reinforced concrete column with confining pressure from prestressing force was derived. When longitudinal reinforcement and stirrup were not taken into consideration and prestressing force was zero, the established formula could be reduced to the computational formula of the axial compression bearing capacity of the ordinary concrete-filled steel tube column.

(2) The section expansion method using ordinary embedded steel bars was used to reinforce this concrete column. The outer diameter of the column was reinforced to $d=700 \mathrm{~mm}$, and the bearing capacity of the column after reinforcement increased by $86.42 \%$ when compared with that of the original column.

(3) When stirrups inside the original column did not bear any stress due to circumferentially applied prestressing force, the bearing capacity of the column after reinforcement increased by $74.26 \%$ when compared with that of the original column.

(4) When the semicircular steel plate reached yield strength because of circumferentially applied prestressing force, the bearing capacity of the column after reinforcement increased by $256.55 \%$ when compared with that of the original column.

(5) The concrete column was reinforced after prestressed semicircular steel plates gathered up, and the steel cylinder formed by a semicircular steel plate, as a compression bar, did not go through critical instability

(6) The working value of axial prestress should not exceed the designed value of the bearing capacity of the original column; otherwise, the original column will be pulled. It is also required that the maximum axial prestress should not exceed the compressive yield strength of the steel plate.

\section{Data Availability}

The authors all agree to share the data underlying the findings of the manuscripts. Data sharing allows researchers to verify the results of an article, replicate the analysis, and conduct secondary analyses. Readers can go through e-mail zhhren81@163.com to ask for the data supporting the conclusions of the study. This paper has no unavailable data, and all data can be released.

\section{Conflicts of Interest}

The authors declare that they have no conflicts of interest.

\section{Acknowledgments}

This work is in part supported by the National Natural Science Foundation of China (Grant no. 51678430), China Postdoctoral Science Foundation (2016M591707), the Natural Science Foundations of Hunan Province (2017JJ4016), the Key Scientific Research Project of Education Commission of Hunan Province (16A050), and the Natural Science Foundations of Hunan Province (2018JJ4042). 


\section{References}

[1] X. Hu, Research on Compressive Performance and Bearing Capacity of RC Short Columns Strengthened with Circular Steel Jacketing, [Ph.D. thesis], Southwest Jiaotong University, 2014.

[2] L. Liu, Study of Bearing Capacity of Reinforced Concrete Short Column Strengthened by Circular Steel Tube under Axial Loading Considering Twice Loading, [Ph.D. thesis], Chengdu University of Technology, 2016.

[3] L. Zhou, X. C. Wang, Y. H. Bai, L. G. Jia, and X. P. Xiang, "Research on mechanical properties of axially loaded steel columns reinforced by outsourcing reinforced concrete while under load," Journal of Engineering Mechanics, vol. 34, no. 1, pp. 192-203, 2017.

[4] J. S. Liu and Y. J. Qian, "Research on bearing capacity of external steel tube reinforced existed ferroconcrete column," Highway Engineering, vol. 41, no. 5, pp. 107-112, 2016.

[5] X. F. Zha, M. X. Lu, B. Yang, and B. Zhao, "The test research on steel tube concrete columns strengthened with outsourcing steel jacketing under low cyclic loading," Journal of Yangtze University (Natural Science Edition), vol. 12, no. 34, pp. 4247, 2015.

[6] T. R. Ou, Study on Axial Compression Performance of RC Columns after Fire Wrapped with Thin-Wall Steel Tube, [Ph.D. thesis], Huaqiao University, 2015.

[7] Y. P. Ni, Study on Compression Performance of Reinforced Concrete Columns after Fire and Wrapped with Thin-Wall Steel Tube, [Ph.D. thesis], Huaqiao University, 2016.

[8] C. Y. Gao, Y. X. Duan, H. Zhang, and H. G. Yang, "Experimental study on the bearing capacity of circular tubed reinforced concrete short column under axial compression," Journal of Building Structures, vol. 47, no. 2, pp. 48-52, 2017.

[9] P. Z. Huang, The Research on Seismic Performance of Column Strengthened with Steel Casing Recycled Concrete, [Ph.D. thesis], South China University of Technology, 2016.

[10] Y. K. Ren, The Research on Seismic Performance of Post Fire Concrete Column Strengthened with External Thin-Walled Steel Tube, [Ph.D. thesis], Huaqiao University, 2015.

[11] M. Fakharifar, G. Chen, C. Wu, A. Shamsabadi, M. A. ElGawady, and A. Dalvand, "Rapid repair of earthquakedamaged RC columns with pre-stressed steel jackets," Journal of Bridge Engineering, vol. 21, no. 4, article 04015075, 2016.

[12] Z. X. Guo, Q. X. Huang, Y. Liu, and Z. Mei, "Prestressed steel jacket for retrofitting reinforcement concrete column," Journal of Engineering Mechanics, vol. 33, no. 3, pp. 1-9, 2016.

[13] X. Z. Zhang, Experimental Study on Axial Compressive Property of Circular Concrete Reinforced Column by Prestressed Steel Strip and Engineering Application, [Ph.D. thesis], Xi'an University of Architecture and Technology, 2014.

[14] L. J. Hao, Research on Axial Compression Performance of Concrete Column Strengthened by Prestressed Steel Belt Reinforced, [Ph.D. thesis], Xi'an University of Architecture and Technology, 2014.

[15] Y. Liu, Z. Q. Gao, J. Y. Lu, L. J. Hao, and S. Y. Li, "Experimental study on column axial compression performance of columns strengthened with prestressed steel strip," Journal of Architecture. Technology, vol. 46, pp. 48-54, 2015.

[16] B. Zhang, Y. Yang, Y. Liu, and K. Q. Zhang, "Experimental study on axial compression performance of reinforced concrete column retrofitted by prestressed steel strip," Journal of Engineering Mechanics, vol. 33, no. 3, pp. 104-111, 2016.
[17] L. Zhang, G. R. Ning, J. H. Li, and Y. Yang, "Experimental study of reinforced concrete columns strengthened by prestressed steel strips," Journal of Industrial Construction, vol. 46, no. 3, pp. 155-159, 2016.

[18] H. D. Wang, L. Zhou, P. H. Deng, and W. C. Sheng, "Seismic performance of RC columns confined by low-prestressed steel belts," Journal of Hunan University (Natural Sciences), vol. 41, no. 2, pp. 19-25, 2014.

[19] Y. Zhao, The Experimental Study on Axial Compression Performance of Concrete Square Columns Strengthened with Prestressed Steel Strip, [Ph.D. thesis], Xi'an University of Architecture and Technology, 2014.

[20] J. T. Zhu and X. L. Wang, "Experimental study on the axial compression performance of damaged concrete column reinforced by CFRP sheets," Earthquake Resistant Engineering and Retrofitting, vol. 1, pp. 100-105, 2015.

[21] M. Shin and B. Andrawes, "Parametric study of RC bridge columns actively confined with shape memory alloy spirals under lateral cyclic loading," Journal of Bridge Engineering, vol. 19, no. 10, article 04014040, 2014.

[22] N. F. Hany, E. G. Hantouche, and M. H. Harajli, “Axial stressstrain model of CFRP-confined concrete under monotonic and cyclic loading," Journal of Composites for Construction, vol. 19, no. 6, article 04015004, 2015.

[23] J. P. Guo, Z. C. Deng, and J. S. Lin, "Experimental study on seismic behavior of RC columns strengthened with prestressed high strength steel wire mesh," Journal of Building Structures, vol. 35, no. 2, pp. 128-136, 2014.

[24] J. H. Zhao, Q. Gu, and S. F. Ma, "The study of the axial compressive strength of concrete filled steel tube (CFST) based on the twin shear unified strength theory," Engineering Mechanics, vol. 19, no. 2, pp. 32-35, 2002.

[25] K. F. Tan, X. C. Pu, and S. H. Cai, "Study on the mechanical properties of steel extra-high strength concrete encased in steel tubes," Journal of Building Structures, vol. 12, no. 1, pp. 10-14, 1999.

[26] M. H. Yu, F. Y. Liu, and F. Liu, "A new general strength theory," China Civil Engineering Journal, vol. 23, no. 1, pp. 3440, 1990.

[27] M. H. Yu, Unified Strength Theory and Its Applications, Springer, 2018.

[28] Z. Guo and X. Shi, Principle and Analysis of Reinforced Concrete, Tsinghua University Press, Beijing, China, 2003.

[29] Z. L. Xu, Elastic Mechanics, Higher Education Press, Beijing, China, 2006.

[30] Z. Q. Zhang, J. H. Zhao, Y. F. Zhang, and X. W. Li, “Axial bearing capacity of composite concrete-filled steel tubular columns," Journal of Chang'an University (Natural Science Edition), vol. 30, no. 1, pp. 67-70, 2010.

[31] J. H. Zhao, X. J. Meng, J. J. Liu, and C. W. Tao, "Bearing capacity of concrete-filled double-skin steel-tube stub column," Journal of Chang'an University (Natural Science Edition), vol. 29, no. 1, pp. 70-74, 2009.

[32] Y. Zhai, J. H. Zhao, L. Ji, and X. Y. Wei, "Unified solutions on axial compressive strength of concrete filled steel tube," Journal of Chang'an University (Natural Science Edition), vol. 26, no. 3, pp. 55-58, 2006.

[33] J. H. Zhao, Strength Theory and Engineering Application, Science Press, Beijing, China, 2003. 


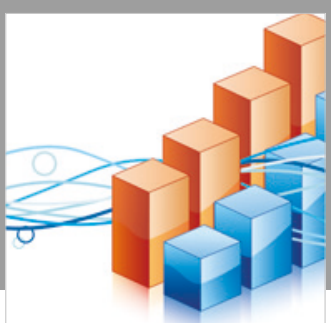

Advances in

Operations Research

\section{-n-m}
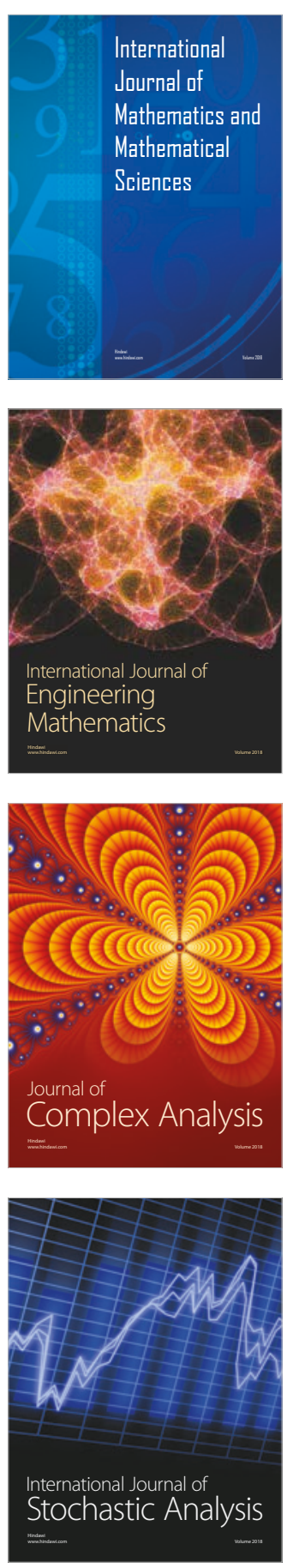
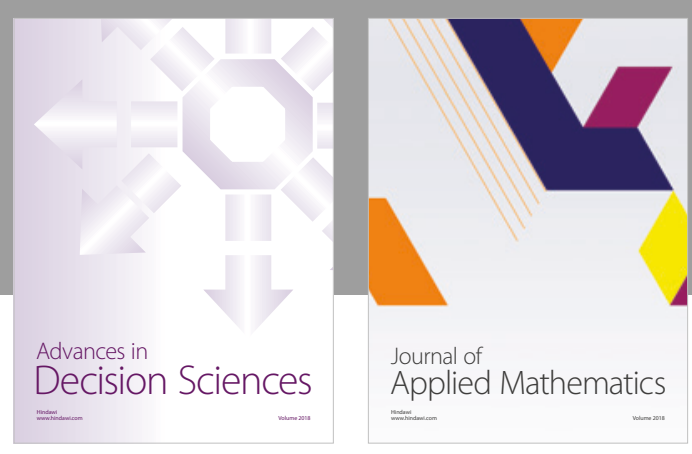

Journal of

Applied Mathematics
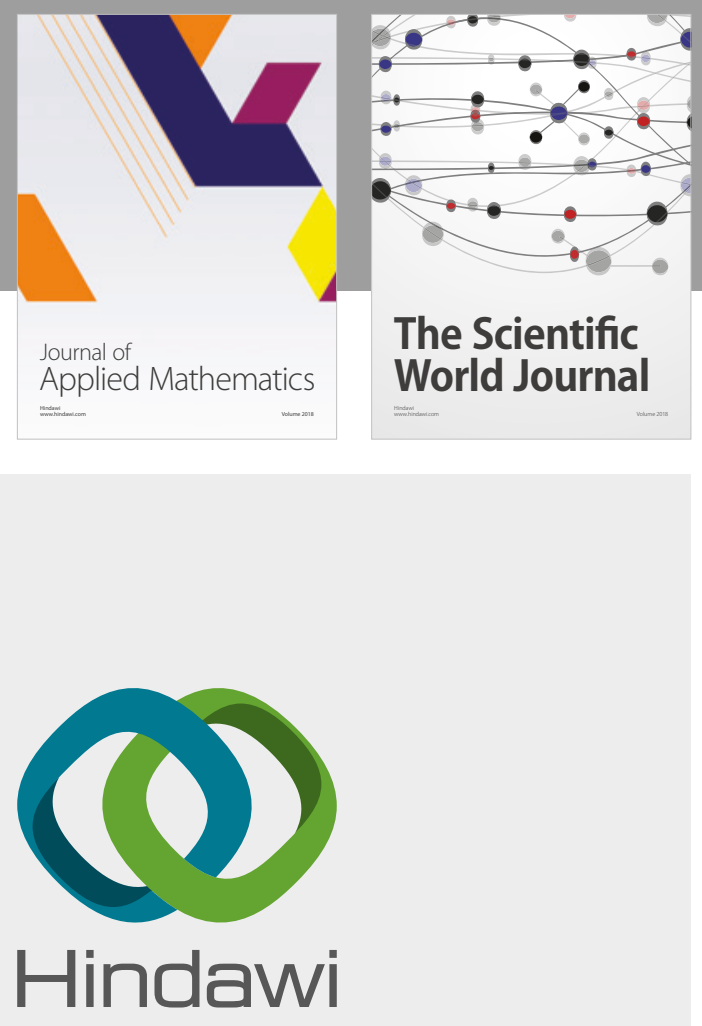

Submit your manuscripts at

www.hindawi.com

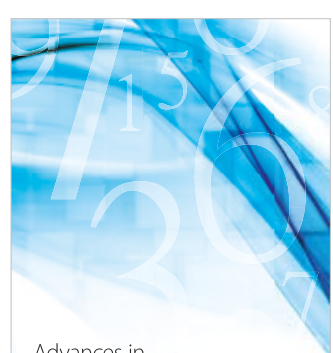

Advances in
Numerical Analysis
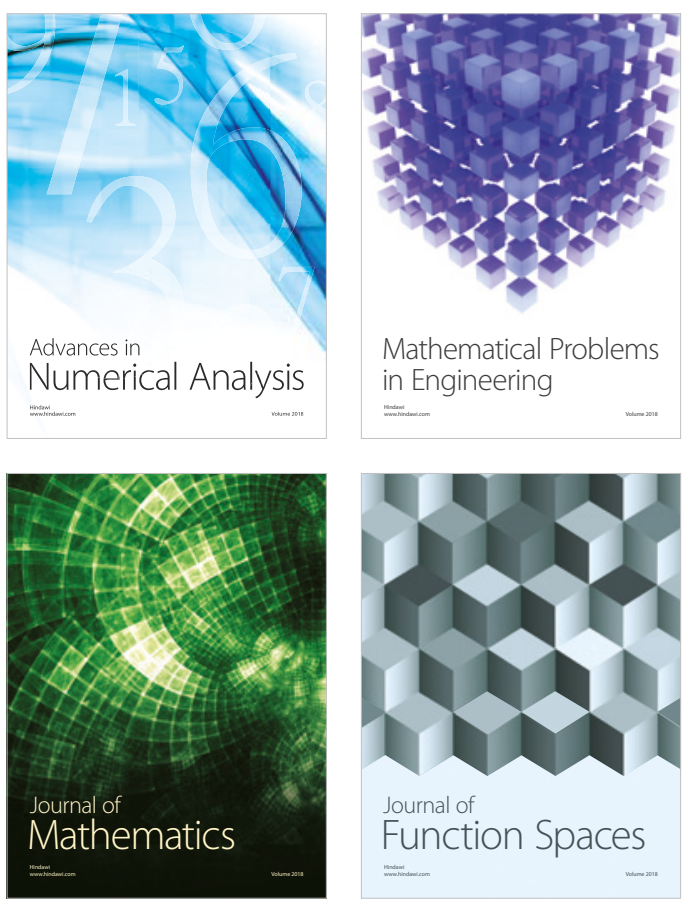

Mathematical Problems in Engineering

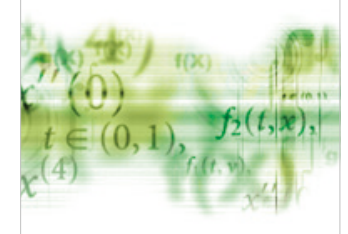

International Journal of

Differential Equations

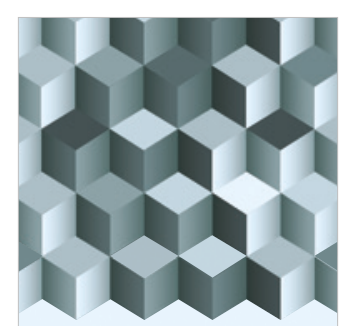

Journal of

Function Spaces
The Scientific

World Journal

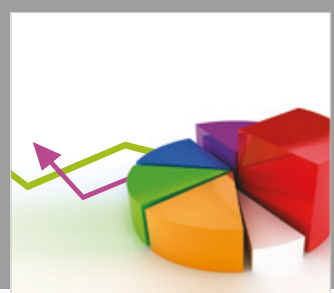

Journal of

Probability and Statistics
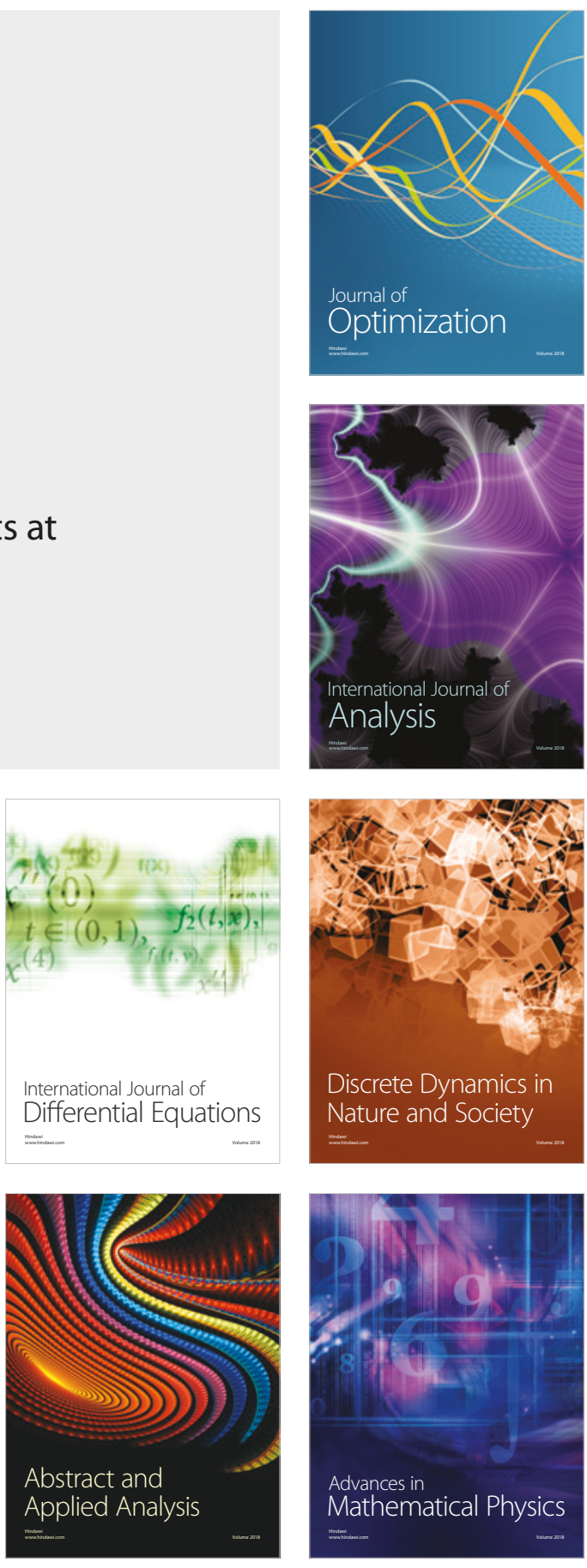